\title{
Giant Serpentine Aneurysm Treated with Double EC-IC Bypass with Thrombectomy and Excision of Aneurysm: A Case Review and Technical Note
}

\author{
Paul E. Kaloostian ${ }^{1}$, Han Chen $^{2 *}$, Howard Yonas ${ }^{2}$ \\ ${ }^{1}$ Johns Hopkins University Medical Center, Baltimore, USA \\ ${ }^{2}$ University of New Mexico Neurological Surgery, Albuquerque, USA \\ Email: *pkaloos1@jhmi.edu
}

Received February 19, 2013; revised March 19, 2013; accepted April 3, 2013

Copyright (C) 2013 Paul E. Kaloostian et al. This is an open access article distributed under the Creative Commons Attribution License, which permits unrestricted use, distribution, and reproduction in any medium, provided the original work is properly cited.

\begin{abstract}
Objective and Importance: The authors report a case of a symptomatic giant serpentine MCA aneurysm treated with double STA-MCA bypass with thrombectomy and excision of aneurysm. This is the first reported case of a double bypass with concomitant thrombectomy and excision of aneurysmal segment. Clinical Presentation/Methods: We report the case of a 27-year-old Hispanic male with severe acute decline in mental status with a giant serpentine MCA aneurysm with significant mass effect and midline shift trapping the lateral ventricular system. Intervention/Results: Patient presented initially to an outside hospital for altered mental status and confusion. Patient was diagnosed with a giant serpiginous aneurysm and hydrocephalus. A left ventriculoperitoneal shunt was placed at the outside hospital and patient was transferred to University of New Mexico. At this time, his mental status declined rather abruptly. He was treated with a double STA-MCA bypass procedure with aneurysm resection.
\end{abstract}

Keywords: Double Bypass; STA-MCA; Serpentine; Aneurysm; Resection; Thrombectomy

\section{Objective and Importance}

The authors present the only known case of a symptomatic giant serpentine MCA aneurysm treated with double STA-MCA bypass with thrombectomy and excision of aneurysm for an acutely declining patient due to mass effect and hydrocephalus.

\section{Clinical Presentation}

We report the case of a 27-year-old Hispanic male with severe acute decline in mental status with a giant serpentine MCA aneurysm with severe mass effect and midline shift trapping the lateral ventricular system.

\section{Intervention}

Patient had a ventriculoperitoneal shunt placed at an outside facility a few days prior to presentation. Upon transfer to University of New Mexico, the patient was comatose and posturing. His imaging studies demonstrated a $10 \mathrm{~cm} \times 6 \mathrm{~cm} \times 9 \mathrm{~cm}$ mass causing acute hydrocephalus with trapping of the lateral ventricular sys-

*Corresponding author. tem due to mass effect (Figure 1).

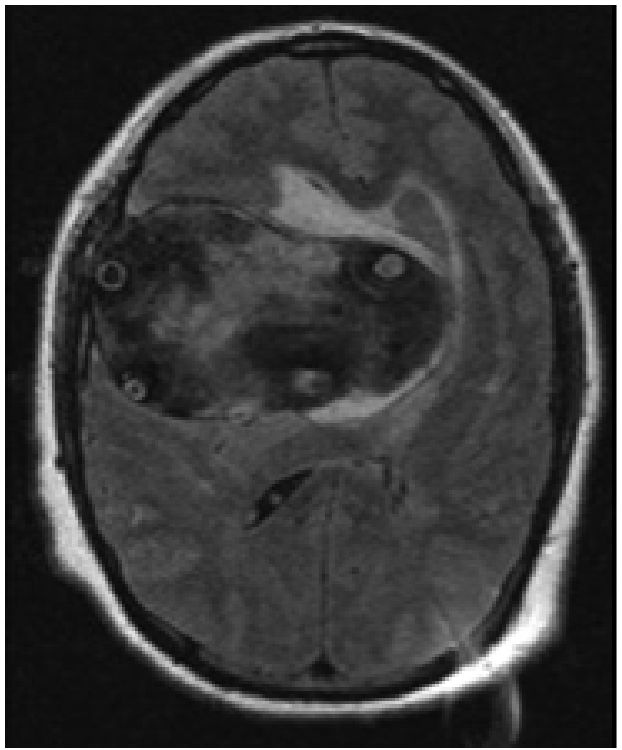

Figure 1. Acute hydrocephalus caused by a $10 \mathrm{~cm} \times 6 \mathrm{~cm} \times$ $9 \mathrm{~cm}$ mass, leading to mass effect-induced trapping of the lateral ventricular system. 
He was taken to the operating room where a double STA-MCA bypass procedure to the distal MCA with aneurysm trapping and decompression was performed. The anterior and posterior divisions of the STA were dissected. A craniotomy was performed and distal M3 vessel was identified and anastomosed with a posterior branch of the STA. Next, the more anterior M2 MCA vessel was identified and dissected from the aneurysm wall and anastomosed with the anterior STA branch. Proximal and distal occlusion was accomplished using aneurysm clips (Figures 1-4). At this point, the serpen-

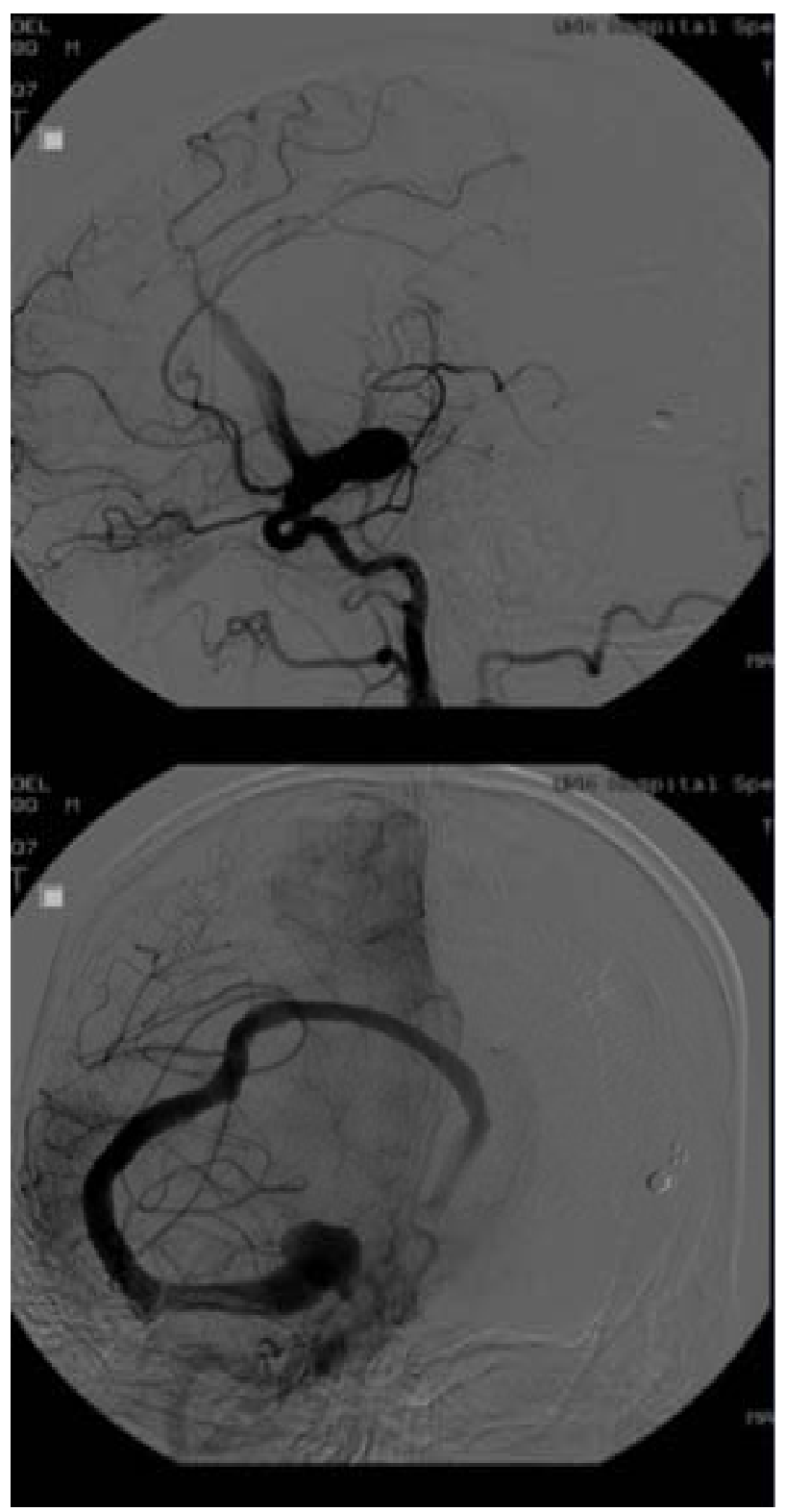

Figures 2. View of the more anterior M2 segment of the MCA vessel identified discussed. This M2 segment was dissected away from the aneurysm wall and anastomosed with the anterior branch of the STA. Proximal and distal occlusion was achieved using aneurysm clips.

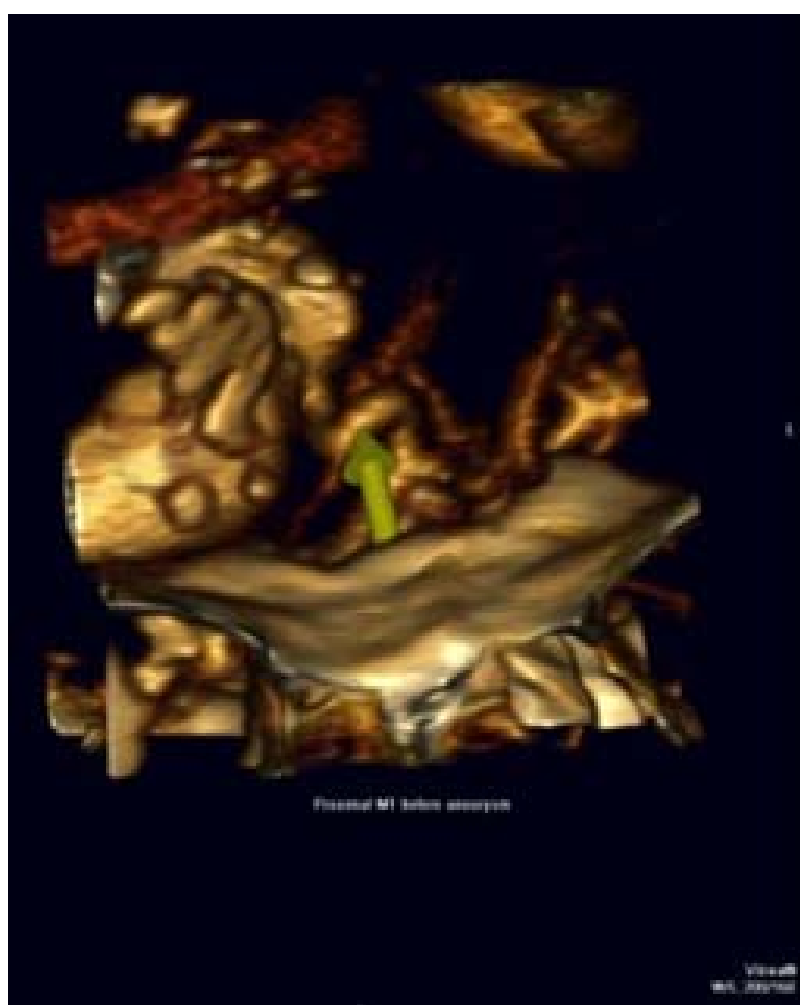

Figures 3. View of the more anterior M2 segment of the MCA vessel identified discussed. This M2 segment was dissected away from the aneurysm wall and anastomosed with the anterior branch of the STA. Proximal and distal occlusion was achieved using aneurysm clips.

tine aneurysm was then opened and the lipid-laden contents were removed with the Cavitron ultrasonic aspiration device. This segment was then aggressively resected. Patient awoke post-operatively over the course of a week. He continued to have left side spasticity but was completely alert and oriented with good strength throughout. On follow up more than 17 months later, CTA studies show intact bypass grafts, with strong temporal artery pulses, and a patient who is applying for medical school (Figures 5-7).

\section{Discussion}

Giant serpentine aneurysms were first described by McLaurin and Segal in 1977 [1]. These anatomically daunting lesions are well characterized in the literature as being larger than $2.5 \mathrm{~cm}$ with a very tortuous long segment of vascular aneurysmal dilatation with mostly thrombosed contents. They classically show areas of calcification with larger lesions demonstrating moderate to severe mass effect [2]. These lesions may cause hydrocephalus, headaches, contralateral hemiparesis, and seizures [3]. It is described that the origin of these lesions resides in the evolution of an initial fusiform aneurysm that then expands and grows due to repeated intramural 


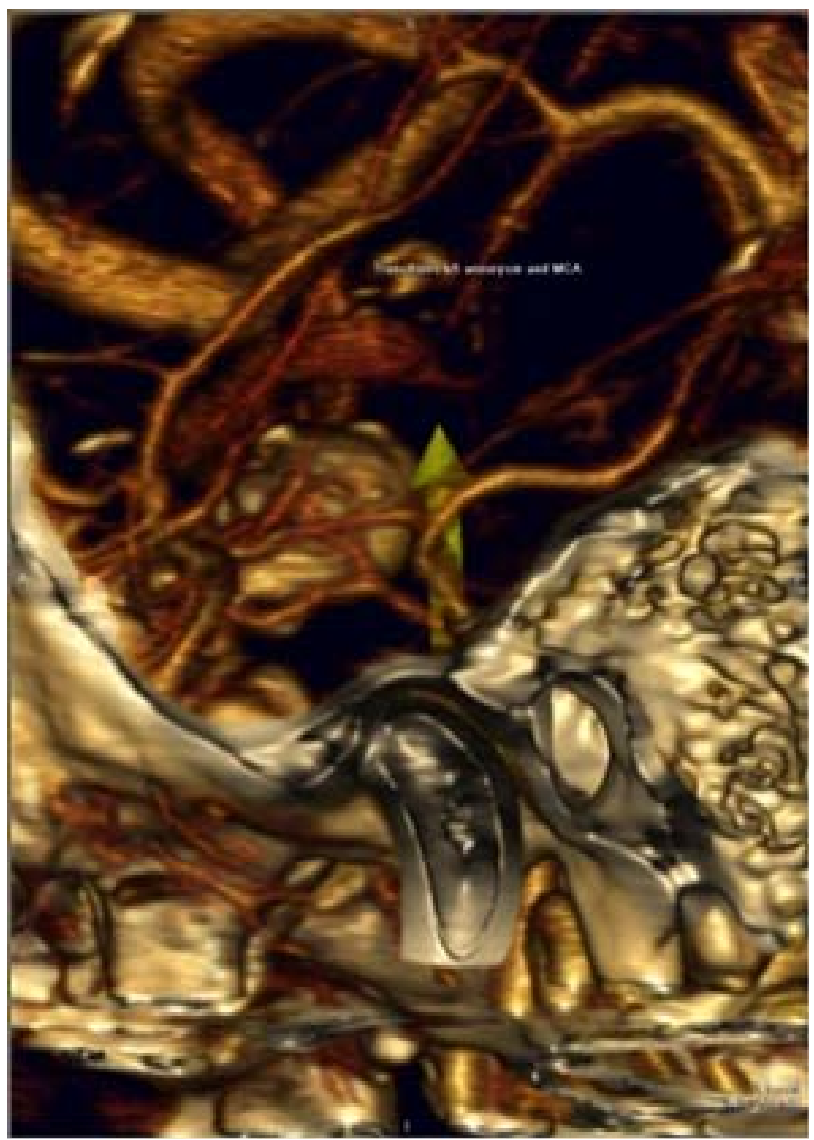

Figures 4. View of the more anterior M2 segment of the MCA vessel identified discussed. This M2 segment was dissected away from the aneurysm wall and anastomosed with the anterior branch of the STA. Proximal and distal occlusion was achieved using aneurysm clips.

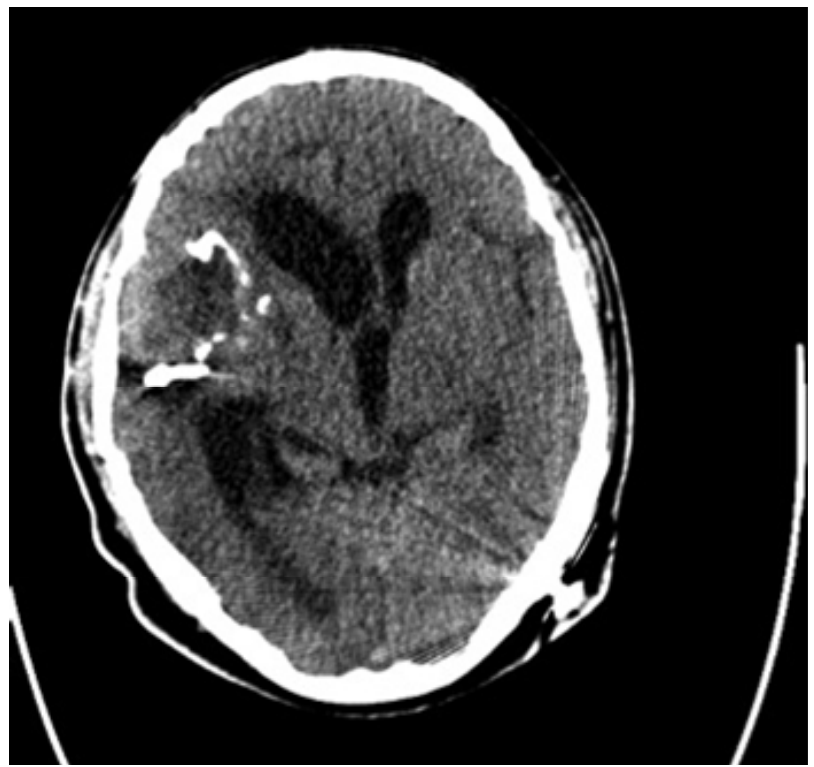

Figures 5. Over 17 months later, CTA studies demonstrating intact bypass grafting. Clinically, the patient demonstrated strong temporal artery pulsations.

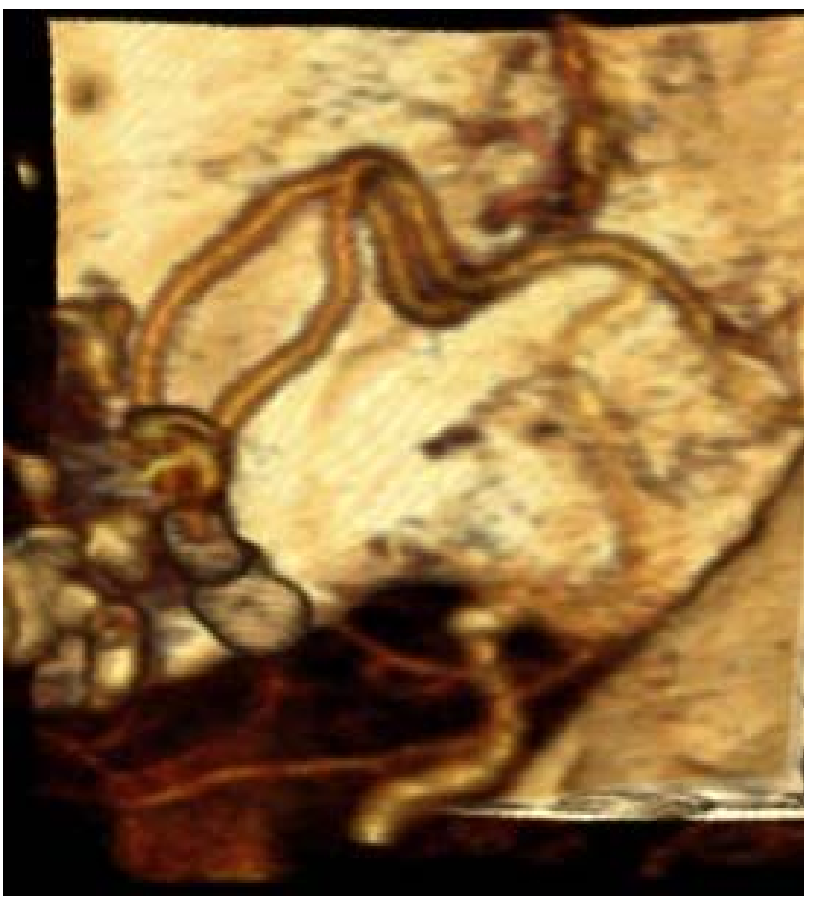

Figures 6. Over 17 months later, CTA studies demonstrating intact bypass grafting. Clinically, the patient demonstrated strong temporal artery pulsations.

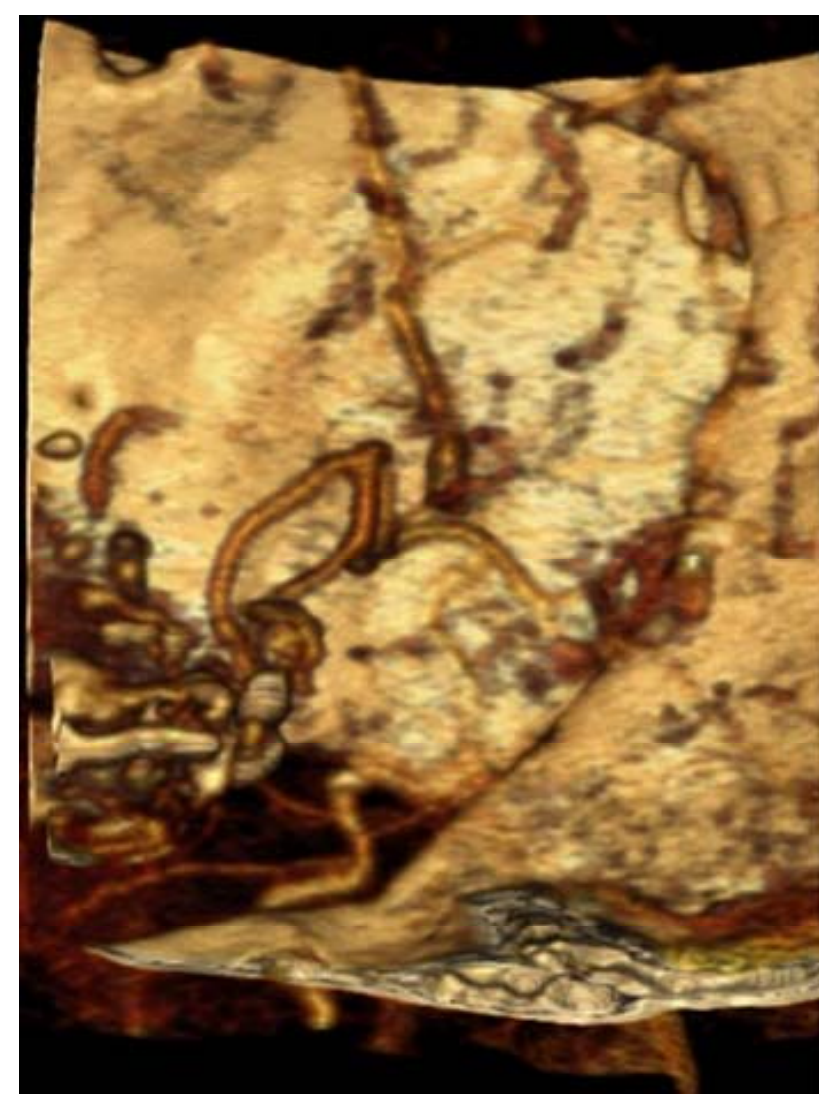

Figures 7. Over 17 months later, CTA studies demonstrating intact bypass grafting. Clinically, the patient demonstrated strong temporal artery pulsations. 
hemorrhage and re-hemorrhage from a weak area along an arterial wall [4]. It is reported that MCA vessels are the most common site of giant serpentine aneurysm formation, however, there are reports of these lesions occurring at PCA and vertebrobasilar sites [3,5]. It has been suggested that there is decreased jet flow within this serpentine aneurysm that allows thrombus to form [6].

The natural history of these disorders has not been recorded due to the small number of cases worldwide. However, we have good data from the cases reported.

Some have reported spontaneous occlusion of these lesions, while many more others have documented acute deterioration $[2,4,7]$. There are also reports of recanalization of these giant lesions leading to neurological deficits [8]. Suzuki et al. reported follow-up angiographic data on their 39 patients showing enlargement of these lesions in 12 of their patients. This demonstrated that indeed these lesions can be very active [9]. In addition to the potential for severe mass effect from these lesions, it has been documented that up to $28 \%$ in Suzuki et al. series presented with acute subarachnoid hemorrhage [10].

Treatment strategies have improved dramatically over the years. Initially, mortality rates were noted to be up to $33 \%$. Carotid ligation was the initial treatment of choice with high rates of poor outcome [2,11]. Surgery seems to be the more optimal treatment for these lesions based on a variety of case series and reports. Suzuki et al. have one of the largest series of patients. They followed 18 patients conservatively and 12 patients surgically. They noted that all their surgical patients showed neurological improvement while five of the six conservatively treated patients declined abruptly [10]. Amin-Hanjani et al. reported a case treated with STA-MCA bypass and proximal MCA clipping with good outcome and patent graft 13 years later, while Horowitz et al. reported a case treated with single STA-MCA bypass with distal outflow clip application and retrograde thrombosis [7,12]. Recently, endovascular strategies to treat this problem have surfaced with some successful reports. However, this has not been shown to be beneficial in patients with severe mass effect and hydrocephalus from these lesions [13].

Giant serpentine aneurysms are challenging lesions to treat. There is no standard approach to treat these lesions. Increasingly, bypass surgery to maintain vital distal flow has been utilized allowing thrombosis and elimination of the mass caused by the thrombosed giant aneurysm. In our patient, the lesion caused acute deterioration from mass effect and hydrocephalus requiring a more emergent surgical treatment. By doing so, we were able to provide immediate relief of mass effect, resolution of hydrocephalus, and continued distal cerebral blood flow.

\section{REFERENCES}

[1] H. D. Segal and R. L. Mclaurin, "Giant Serpentine Aneu- rysm: Report of Two Cases,” Journal Neurosurgery, Vol. 46, No. 1, 1977, pp. 115-120.

doi:/10.3171/jns.1977.46.1.0115

[2] V. A. Aletich, G. M. Debrun, L. H. Monsein, H. J. Nauta and R. F. Spetzler, "Giant Serpetine Aneurysm: A Review and Presentation of Five Cases,” American Journal of Neuroradiology, Vol. 16, 1995, pp. 1601-1072.

[3] L. D. Christiano, G. Gupta, C. J. Prestigiacomo and C. D. Gandhi, "Giant Serpentine Aneurysms," Neurosurgical Focus, Vol. 26, No. 5, 2009, p. E5.

doi:/10.3171/2009.2.FOCUS0918

[4] R. R. Lukin, A. A. Chambers, R. McLaurin and J. Tew Jr., “Thrombosed Giant Middle Cerebral Aneurysms," Neuroradiology, Vol. 10, No. 3, 1975, pp. 125-129. doi:/10.1007/BF00341812

[5] A. Mahadevan, R. Tagore, N. M. Siddappa, V. Santosh, T. C. Yasha, U. Ranga, et al., "Giant Serpentine Aneurysm of Vertebrobasilar Artery Mimicking Dolichoectasia-An Unusual Complication of Pediatric AIDS. Report of a Case with Review of the Literature," Clinical Neuropathology, Vol. 27, No. 1, 2008, pp. 37-52.

[6] N. F. Fanning, M. O. Kelleher and D. Q. Ryder, "The Pretzel Sign: Angiographic Pattern of Tortuous IntraAneurysmal Blood Flow in a Giant Serpentine Aneurysm,” British Journal of Neurosurgery, Vol. 17, 2003, pp. 67-71.

[7] M. B. Horowitz, H. Yonas, C. Jungreis and T. K. Hung, "Management of a Giant Middle Cerebral Artery Fusiform Serpentine Aneurysm with Distal Clip Application and Retrograde Thrombosis: Case Report and Review of the Literature,” Surgical Neurology, Vol. 41, No. 3, 1994, pp. 221-225. doi:/10.1016/0090-3019(94)90126-0

[8] K. C. Lee, J. Y. Joo, K. S. Lee and Y. S. Shin, "Recanlization of Completely Thrombosed Giant Aneurysm: Case Report,” Surgical Neurology, Vol. 51, No. 1, 1999, pp. 94-98.

[9] A. Sari, S. Kandemir, L. Kuzeyli and H. Dinc, "Giant Serpentine Aneurysm with Acute Spontaneous Complete Thrombosis,” American Journal of Neuroradiology, Vol. 27, 2006, pp. 766-768.

[10] S. Suzuki, T. Takahashi, H. Ohkuma, T. Shimizu and S. Fujita, "Management of Giant Serpentine Aneurysms of the Middle Cererbral Artery: Review of Literature and Report of Case Successfully Treated by STA-MCA Anastomosis Only," Acta Neurochirurgica, Vol. 117, No. 1-2, 1992, pp. 23-29. doi:/10.1007/BF01400630

[11] M. Scott and E. Skwarok, "The Treatment of Cerebral Aneurysms by Ligation of the Commone Carotid Artery," Surgery Gynecology \& Obstetrics, Vol. 113, 1961, pp. 54-61.

[12] S. Amin-Hanjani, P. R. Chen, S. W. Chang and R. F. Spetzler, "Long Term Follow up of Giant Serpentine MCA Aneurysm Treated with EC-IC Bypass and Proximal Occlusion," Acta Neurochirurgica, Vol. 148, No. 2, 2006, pp. 227-228. doi:/10.1007/s00701-005-0691-3

[13] W. J. Van Rooij, M. Sluzewski and G. N. Beute, "Endovascular Treatment of Giant Serpentine Aneurysms," American Journal of Neuroradiology, Vol. 29, 2008, pp. 1418-1419. doi:/10.3174/ajnr.A1071 